\title{
New biotechnology enhances the application of cisgenesis in plant breeding
}

\author{
Hongwei Hou ${ }^{1,2,3} *$, Neslihan Atlihan ${ }^{2,3}$ and Zhen-Xiang Lu ${ }^{2} *$ \\ ${ }^{1}$ Institute of Hydrobiology, Chinese Academy of Sciences, Wuhan, China \\ ${ }^{2}$ Lethbridge Research Centre, Agriculture and Agri-Food Canada, Lethbridge, AB, Canada \\ ${ }^{3}$ Central Research Institute of Food and Feed Control, Bursa, Turkey
}

Edited by:

Jun Yu, Beijing Institute of Genomics, China

\section{Reviewed by:}

Clifford Weil, Purdue University, USA

Steven B. Cannon, United States

Department of Agriculture -

Agricultural Research Service, USA

\section{*Correspondence:}

Hongwei Hou, Institute of

Hydrobiology, Chinese Academy of

Sciences, 7 Donghu Road South,

Wuhan, Hubei 430072, China

e-mail: houhw@ihb.ac.cn;

Zhen-Xiang Lu, Lethbridge Research

Centre, Agriculture and Agri-Food

Canada, 5403 - 1 Avenue South,

Lethbridge P. O. Box 3000,

Lethbridge, AB, Canada

e-mail: zhen-xiang.lu@agr.gc.ca
Cisgenesis is genetic modification to transfer beneficial alleles from crossable species into a recipient plant. The donor genes transferred by cisgenesis are the same as those used in traditional breeding. It can avoid linkage drag, enhance the use of existing gene alleles. This approach combines traditional breeding techniques with modern biotechnology and dramatically speeds up the breeding process. This allows plant genomes to be modified while remaining plants within the gene pool. Therefore, cisgenic plants should not be assessed as transgenics for environmental impacts.

Keywords: cisgenesis, crop breeding, genetically modified organism, safety evaluation, plant biotechnology

\section{INTRODUCTION}

Increasing world population and food demands require world agricultural production be increased by $50 \%$ by 2030 (The Royal Society, 2009). In the meantime, climate change and shrinking environmental resources are limiting agricultural production over the world (Lobell et al., 2008). These challenges bring an urgent need to enhance crop productivity. To breed crops with increased yield and resistance to environment stresses, a pivotal consideration is how to effectively utilize genetic diversity.

Genetic crossing, selection of natural or artificial mutations, and transgenics, are the main techniques for plant breeding. Traditional plant breeding uses crossing, mutagenesis and somatic hybridization for genome modification to improve crop traits. It introduces new beneficial alleles from crossable species. Due to crossing barriers and linkage drag, however, traditional plant breeding is time-consuming and requires several generations of breeding and selection. Transgenic breeding uses molecular cloning techniques to identify cloned or synthesized genes of interest and directly transforms the recipient genome. This process manipulates plant genomes through insertion of gene(s) from another species. An organism that is generated this way is considered to be a genetically modified organism (GMO). Transgenic plants have been created with better tolerance against natural stresses, and to produce biofuels, vaccines, and antibodies (Ahmad et al., 2012). Many plant species, including major crops such as rice, soybean, maize, cotton, canola, potato, cassava, squash, papaya, groundnut, oilseeds, and numerous vegetables and fruits have foreign genes inserted in their genomes (Mendoza et al., 2008; Chakraborty et al., 2010;
Hutchison et al., 2010; Llorente et al., 2010; Motoyama et al., 2010; Asif et al., 2011). However, transgenic crops have brought considerable concerns about their safety and impact on health and the environment. This is because exogenous genes from other species such as bacteria, or synthesized DNA such as DNA borders are transferred to plant genomes, and the sites of insertion are random, which may have unpredictable side effects.

Recent progress in plant genome sequencing facilitates the isolation of plant genes from crossable species. These genes are called cisgenes. Increasing numbers of these cisgenes have been isolated and new transformation protocols have been developed, which do not leave marker genes behind. This allows plant genomes to be modified while remaining plants within the gene pool. This new breeding approach was first called cisgenesis by Schouten et al. (2006), who defined a cisgenic plant as "a crop plant that has been genetically modified with one or more genes isolated from a crossable donor plant." In the scientific opinion of the [European Food Safety Authority (EFSA), 2012], cisgenesis is described as specific alleles/genes in the breeder's gene pool are introduced into new varieties without the accompanying linkage drag (co-transfer of DNA sequences that are linked to the gene of interest) which occurs in conventional breeding. In contrast, a transgenic plant receives gene(s) from a non-plant organism, or from a donor plant that is sexually incompatible with the recipient plant. For example, the introduction of the $R 1$ gene, the first gene for resistance to late-blight, from wild type potato (Solanum demissum) to cultivated potato (S. tuberosum) is cisgenesis. However, the transfer of the Bt gene from the bacteria Bacillus 
thuringiensis to cotton genome to produce pest resistant cotton is transgenesis.

Cisgenic plants are more likely to be acceptable to the public than transgenic plants. According to a survey in the USA, 55$77 \%$ of people who participated would eat a cisgenic or intragenic vegetable (depending on number of genes and source of the gene) whereas $17-25 \%$ of them would eat the vegetable if it contained a gene from a microorganism or an animal. In another survey in Mississippi, $81 \%$ would eat a cisgenic or intragenic vegetable, while only $14-23 \%$ would eat a transgenic vegetable containing non plant sources (Viswanath and Strauss, 2010). In the EU, cisgenic plants are expected to be more acceptable for consumers (Herzog, 2012).

\section{CISGENESIS IS DRAMATICALLY IMPROVING EFFICIENCY IN USE OF SUPERIOR ALLELES}

In traditional breeding, obtaining desired traits is painstakingly slow and one challenge is the low affinity between wild and cultivated varieties. Techniques such as embryo rescues, cross bridges and somatic cell hybridization help overcome this obstacle. An example of their use is in breeding late-blight resistant potato. By using traditional breeding, Hermsen and Ramanna (1973) overcame numerous obstacles to establish double bridge hybrids of S. bulbocastanum and cultivars of S. tuberosum. They used wild varieties of $S$. acaule and $S$. phureja as bridge parents to introduce the late-blight resistance trait from $S$. bulbocastanum to cultivars of $S$. tuberosum, resulting in so-called ABPT material, which is used widely for breeding late-blight resistant potato varieties. The first late-blight resistant potato variety "Biogold" was developed and released 30 years later. In contrast to such long term traditional breeding, van der Vossen et al. (2003, 2005) applied the cisgenesis breeding approach and successfully cloned and introduced three late-blight resistance genes from S. bulbocastanum to cultivated potato within only a few years.

Another obstacle in traditional breeding is linkage drag. This problem can only be solved by many generations of backcrosses and screening for recombination, which is uncoupling the wanted trait from those traits that are unwanted (Jacobsen and Schouten, 2007). Such a process is time-consuming, especially for crops with a long generation period. The problem is even more serious if several genes from different wild sources have to be accumulated, e.g., for durable resistance. This could be prevented if only the gene(s) of interest was added, leaving the undesired genes in the wild germplasm behind. Using isolated cisgenes coding only for wanted traits could drastically overcome these problems, because cisgenesis allows genes containing their native introns, promoters, and terminators to be introduced into cultivated varieties. An example is breeding apples for scab (Venturia inaequalis) resistance. Introgression of the apple scab resistance gene $V f$ from Malus floribunda 821 into marketable high quality apple cultivars started in the 1950s (Hough et al., 1953), and breeding continued for more than 50 years. This slow tempo is mainly caused by the long juvenile period of apple trees and the phenomenon that not only the allele of interest is inherited by the progeny, but also hundreds of unwanted alleles. For durable resistance, different resistance genes must be accumulated, but this may take a few more decades. The process would be much faster to achieve by cisgenesis, which combines the knowledge of native alleles with marker-free technologies and allows the introduction of resistance-gene alleles without associated selection genes.

There are a number of examples of the successful use of cisgenesis in developing improved crops. In a project named Durable Resistance against Phytophthora (DuRP), a cisgenic strategy was used to develop potatoes resistant to late-blight. Haverkort et al. (2009) tried several ways to clone genes from susceptible and resistant plants of selected wild species. The $\mathrm{R}$ genes or a cassette of several $\mathrm{R}$ genes were transferred to potato leaf cells via Agrobacterium tumefaciens. A marker was used only for the fast determination of the best $\mathrm{R}$ gene combination. After that step, the desired potatoes with these genes were modified in a marker-free way. The field trials of potato crops produced during this project are ongoing in Belgium, Ireland, and the Netherlands (Holme et al., 2013).

Cisgenesis has also been successfully applied in cereal crops and trees. In barley, a marker-free cisgenic variety has been developed, with an extra phytase gene introduced to enhance phosphate bioavailability by degrading phytic acid enzymatically (Holme et al., 2012). Using the pClean dual binary vector system with hygromycin resistance for selection, two T1 lines were identified containing a single purple acid phosphatase (PAP) insert (both hygromycin and kanamycin resistance genes had been removed). Field trials are being carried out in Denmark, with a 2012-2016 release period (Holme et al., 2013). In durum wheat, Gadaleta et al. (2008) conducted biolistic transformation to enhance bread making properties. Wheat $\mathrm{D}$ genome genes encoding the $1 \mathrm{D} \times 5$ and 1 Dy10 glutenin subunits with their own native endosperm promotors and terminators were cloned and transferred. As a positive selectable marker, Escherichia coli phosphomannose isomerase (pmi) was removed from minimal gene cassettes under genetic segregation and positive selection. In poplar trees, the effects on plant growth from insertion of five cisgenes that encode proteins for gibberellin metabolism or signaling have been studied (Han et al., 2011). All parts of cisgenes, including their promoter and terminator, were transferred into the Populus trichocarpa genome. Three of the cisgenic modifications had significant effects on either plant growth rate, morphology or wood properties.

Thus cisgenic insertion of additional copies of native genes may provide a new approach to modify plant genomes, expand genetic variance in plant architecture available to breeders and accelerate the transfer of alleles between species which are difficult to cross.

\section{NEW BIOTECHNOLOGY IS MAKING CISGENESIS INCREASINGLY FEASIBLE IN USE OF GENE RESOURCES}

The bottleneck in modern crop breeding is the limited genetic variability in any one crop species, since the plant breeding process has selected only superior genotypes in which the genetic variation is reduced (Simmonds, 1993; Tanksley and McCouch, 1997). Such limitation of crop genetic variations is a major concern because it may result in widespread losses in crop yield and quality if new pathogen populations or unusual abiotic stresses occur. Incorporation of new alleles from wild germplasm that confer pathogen 
resistance, can alleviate this genetic vulnerability (Maunder, 1992; Cox and Wood, 1999).

Plant genome sequencing facilitates the isolation of cisgenes from crossable crops or wild species. Cost-effective highthroughput sequencing techniques have been invented that allow a whole plant genome to be sequenced in a few days rather than a few years as in the past. From just a few model species originally, now whole genomes of a wide variety of organisms can be sequenced. Currently, genomes of more than 180 organisms have been sequenced since 1995. This provides more varieties of gene resources for manipulation, which facilitates the isolation of cisgenes from crossable crops or wild species. In the meantime, efficient gene isolation methods, such as map-based cloning and allele mining, open new avenues in plant breeding by using cloned indigenous genes. Furthermore, advances in plant molecular biology have greatly facilitated the isolation of plant genes associated with economically important traits (Pereira, 2000), which provides alternative approaches to those that rely on genetic variation that has evolved in unrelated species.

\section{NEW BIOTECHNOLOGY IS MAKING CISGENESIS INCREASINGLY FEASIBLE FOR PRECISELY OBTAINING NEW AGRICULTURAL TRAITS}

To avoid the introduction of exogenous genes, new transformation protocols, without bacterial selection markers, have been developed (McKnight et al., 1987; de Vetten et al., 2003; Schaart et al., 2004). To circumvent the need for using bacterial T-DNAs, the isolated genes are inserted into species-specific P-DNAs (de Vetten et al., 2003; Rommens, 2004).

Application of new methods, such as promoter trapping and RNA fingerprinting, has resulted in the isolation of native regulatory elements that can now be exploited for the precise expression of the desired traits (Meissner et al., 2000; Trindade et al., 2003).

Gene editing techniques, such as the use of zinc finger nucleases (ZFNs) and transcription activator-like effectors nucleases (TALEN), allow site-directed modifications in the genes of interest. ZFNs are hybrid enzymes composed of a naturally occurring FokI restriction endonuclease and zinc finger DNA binding domains (Curtin et al., 2012). Zinc finger proteins recognize and bind to target sequences and FokI nuclease catalyze cleavage of DNA base pairs downstream of the recognition site. Each zinc finger protein recognizes three particular base pairs in target DNA (de Pater et al., 2009). In Arabidopsis, de Pater et al. (2009) generated ZFNs with six zinc fingers which can recognize 18 base pairs in target DNA to introduce mutations. ZFNs has also been used to induce mutations in tobacco (Townsend et al., 2009) and maize (Shukla et al., 2009). TALEN are proteins produced by the plant pathogenic bacterium Xanthomonas and bind to specific DNA sequences (Curtin et al., 2012). Together with endonuclease FokI, TALEN has been used to introduce mutations in Arabidopsis, tobacco protoplasts and leaves, rice and Brachypodium (Curtin et al., 2012; Shan et al., 2013; Zhang et al., 2013). There are several open engineering platforms available for construction of ZFNs and TALENs (Townsend et al., 2009; Curtin et al., 2012; Zhang et al., 2013).

Recently, the clustered regulatory interspaced short palindromic repeats (CRISPR) associated nuclease (Cas) system has been reported to be an efficient and highly specific method for gene editing (Feng et al., 2013; Upadhyay et al., 2013). Cas is a protein catalyzing DNA cleavage. CRISPR consists of variable short spacer sequences separated by short repeat sequences and these CRISPR arrays are transcribed into non-coding RNAs (Jinek et al., 2013). CRISPR-Cas mediated genome editing has been reported in wheat (Triticum aestivum) and Nicotiana benthamiana (Upadhyay et al., 2013), as the mutations were induced in inositol oxygenase (inox) and phytoene desaturase ( $p d s$ ) genes in wheat and $p d s$ gene in N. benthamiana, respectively. This system has also been used to introduce mutations in the OsMPK5 gene which encodes a stressresponsive protein kinase in the rice genome (Xie and Yang, 2013) and the mutations of several genes in Arabidopsis and rice (Feng et al., 2013).

Several methods have been developed to remove selectable marker genes from the genomes of transgenic plants. One approach exploits an inducible recombination system to excise a marker gene positioned between recombination sites (Zuo et al., 2001) and another strategy relies on the segregation of independently integrated T-DNAs (Komari et al., 1996). New and efficient Agrobacterium-based methods that utilize a plant-derived transfer DNA and a novel transient selection system to insert only native DNA into potato plants have been invented (Rommens et al., 2004). However, the majority of these methods for production of cisgenic crops have been patented, therefore scientists need either to use these patents or design new methods to eliminate the undesired DNA sequences from host genomes (Holme et al., 2013).

\section{CISGENIC PLANTS SHOULD BE DISTINGUISHED FROM TRANSGENIC PLANTS}

The release of genetically modified (GM) plants is currently regulated to prevent any negative effects on the environment or human health. These regulations are based on transgenic organisms and do not distinguish transgenic plants from cisgenic plants. This means that the GM-regulations for transgenes (genes from the non-crossable species), are also applied for cisgenes (genes from crossable species). However, cisgenesis is more similar to traditional plant breeding than is transgenesis. There is a great necessity to distinguish cisgenesis from transgenesis.

Although both transgenesis and cisgenesis use the same genetic modification techniques to introduce gene(s) into a plant, cisgenesis introduce only genes of interest from the plant itself or from a crossable species, and these genes could also be transferred by traditional breeding techniques. Therefore, cisgenesis is not any different from traditional breeding or that which occurs in nature. There is no environmental risk evoked and release of cisgenic plants into the environment is as safe as that of traditionally bred plants.

If the current international GMO regulations continue to fail in distinguishing cisgenic from transgenic plants, the use of cisgenesis could be seriously hindered. Only Canada now has a product-based regulation system rather than a process-based one and this has made it legally possible to control cisgenic plants less strictly than transgenic plants. Any restrictions on cisgenesis could block or delay further research and application of improved crop varieties, especially at a time when increasing number of genes 
from crops and their crossable wild relatives are being isolated and are becoming amenable to cisgenesis. In Australia, cisgenic plants are treated differently under GMO regulations, as stated in Gene Technology Regulations that "a mutant organism in which the mutational event did not involve the introduction of any foreign nucleic acid" is not specified as GMO (Russell and Sparrow, 2008).

European Food Safety Authority has released a scientific assessment of the safety assessment of plants developed through cisgenesis and intragenesis. According to this report concerning the source of introduced genes, cisgenesis has similar hazards as does traditional breeding. However, the transformation techniques used in cisgenesis and transgenesis are the same, so they have similar risk linked to transfer technology. This report recommended to using the same risk assessment guides as used in transgenic plants to evaluate the cisgenic plants, but the required information might be less than that needed for transgenic plants [European Food Safety Authority (EFSA), 2012].

\section{CONCLUDING REMARKS AND PERSPECTIVES}

Traditional breeding provides us excellent plants with many genes working together in a concerted manner. Plant breeders may have a limited knowledge of the underlying genetic networks, but they are still able to develop superior crop cultivars. Because of the complexity of plant functions, traditional breeding has been widely used and will remain crucially important for agricultural production. Cisgenesis is the transfer of gene(s) from the recipient plant itself, or from a donor plant that is sexually compatible with the recipient plant. Knowledge of traditional breeding remains critical for selection of cisgenic plants in breeding by cisgenesis. New biotechnology is making cisgenesis increasingly feasible in use of gene resources and precisely obtaining new agricultural traits without insertion of foreign genes or gene fragments.

\section{REFERENCES}

Ahmad, P., Ashraf, M., Younis, M., Hu, X., Kumar, A., Akram, N. A., et al. (2012). Role of transgenic plants in agriculture and biopharming. Biotechnol. Adv. 30, 524-540. doi: 10.1016/j.biotechadv.2011.09.006

Asif, M. A., Zafar, Y., Iqbal, J., Iqbal, M. M., Rashid, U., Ali, G. M., et al. (2011). Enhanced expression of AtNHX1, in transgenic groundnut (Arachis hypogaea L.) improves salt and drought tolerance. Mol. Biotechnol. 49, 250-256. doi: 10.1007/s12033-011-9399-1

Chakraborty, S., Chakraborty, N., Agrawal, L., Ghosh, S., Narula, K., Shekhar, S., et al. (2010). Next-generation protein-rich potato expressing the seed protein gene AmA1 is a result of proteome rebalancing in transgenic tuber. PNAS 107, 17533-17538. doi: 10.1073/pnas. 1006265107

Cox, T. S., and Wood, D. (1999). "The nature and role of crop biodiversity," in Agrobiodiversity: Characterization, Utilization, and Management, eds D. Wood and J. M. Lenne (Wallingford, UK: CABI Publishing), 35-57.

Curtin, S. J., Voytas, D. F., and Stupar, R. M. (2012). Genome engineering of crops with designer nucleases. Plant Genome. 5, 42-50. doi: 10.3835/plantgenome2012.06.0008

de Pater, S., Neuteboom, L. W., Pinas, J. E., Hooykaas, P. J. J., and van der Zaal, B. J. (2009). ZFN-induced mutagenesis and gene-targeting in Arabidopsis through Agrobacterium-mediated floral dip transformation. Plant Biotechnol. J. 7, 821835. doi: 10.1111/j.1467-7652.2009.00446.x

de Vetten, N., Wolters, A. M., Raemakers, K., van der Meer, I., terStege, R., Heeres, E., et al. (2003). A transformation method for obtaining marker free plants of a cross-pollinating and vegetatively propagated crop. Nat. Biotech. 21, 439-442. doi: $10.1038 /$ nbt801
European Food Safety Authority [EFSA]. (2012). Scientific opinion addressing the safety assessment of plants developed through cisgenesis and intragenesis. EFSA J. 10, 2561.

Feng, Z., Zhang, B., Ding, W., Liu, X., Yang, D. L., Wei, P., et al. (2013). Efficient genome editing in plants using a CRISPR/Cas system. Cell Res. 23, 1229-1232. doi: 10.1038/cr.2013.114

Gadaleta, A., Giancaspro, A., Blechl, A. E., and Blanco, B. (2008). A transgenic durum wheat line that is free of marker genes and expresses 1Dy10. J. Cereal Sci.48, 439-445. doi: 10.1016/j.jcs.2007.11.005

Han, K. M., Dharmawardhana, P., Arias, R. S., Ma, C., Busov, V., and Strauss, S. H. (2011). Gibberellin-associated cisgenes modify growth, stature and wood properties in Populus. Plant Biotechnol. J. 9, 162-178. doi: 10.1111/j.14677652.2010.00537.x

Haverkort, A. J., Struik, P. C., Visser, R.G.F., and Jacobsen, E. (2009). Applied biotechnology to combat late blight in potato caused by Phyophtora infestans. Potato Res. 52, 249-264. doi: 10.1007/s11540-0099136-3

Hermsen, J. G., and Ramanna, M. S. (1973). Double bridge hybrids of Solanum bulbocastanum and cultivars of Solanum tuberosum. Euphytica 2, 457-466. doi: 10.1007/BF00036641

Herzog, U. (2012). Cisgenesis: A Report on the Practical Consequences of the Application of Novel Techniques in Plant Breeding. Available at: http://bmg.gv.at/cms/home/attachments/6/6/0/CH1052/CMS1352183689337/ci sgenesis_20121105.pdf

Holme, I. B., Dionisio, G., Brinch-Pedersen, H., Wendt, T., Madesen, C. K., Vincze, E., et al. (2012). Cisgenic barley with improved phytase activity. Plant Biotechnol. J. 10, 237-247. doi: 10.1111/j.1467-7652.2011.00660.x

Holme, I. B., Wendt, T., and Holm, P. B. (2013). Intragenesis and cisgenesis as alternatives to transgenic crop development. Plant Biotechnol. J. 11, 395-407. doi: 10.1111/pbi.12055

Hough, L. F., Shay, J. R., and Dayton, D. F. (1953). Apple scab resistance from Malus floribunda Sieb. Proc. Amer. Soc. Hort. Sci. 62, 341-347.

Hutchison, W. D., Burkness, E. C., Mitchel, P. D., Moon, R. D., Leslie, T. W., Fleischer, S. J., et al. (2010). Area wide suppression of European corn borer with Bt maize reaps savings to non-Bt maize growers. Science 330, 222-225. doi: 10.1126/science. 1190242

Jacobsen, E., and Schouten, H. J. (2007). Cisgenesis strongly improves introgression breeding and induced translocation breeding of plants. Trends Biotechnol. 25, 219-223. doi: 10.1016/j.tibtech.2007.03.008

Jinek, M., East, A., Cheng, A., Lin, S., Ma, E., and Doudna, J. (2013). RNAprogrammed genome editing in human cells. eLife 2:e00471.

Komari., T., Hiei, Y., Saito, Y., Murai, N., and Kumashiro, T. (1996). Vectors carrying two separate T-DNAs for co-transformation of higher plants mediated by Agrobacterium tumefaciens and segregation of transformants free from selection markers. Plant J. 10, 165-174. doi: 10.1046/j.1365-313X.1996.1001 0165.x

Llorente, B., Rodríguez, V., Alonso, G. D., Torres, H. N., Flawiá, M. M., and Bravo-Almonacid, F. F. (2010). Improvement of aroma in transgenic potato as a consequence of impairing tuber browning. PLoS ONE 5:e14030. doi: 10.1371/journal.pone.0014030

Lobell, D., Burke, M., Tebaldi, C., Mastrandrea, M., Falcon, W., and Naylor, R. (2008). Prioritizing climate change adaptation needs for food security in 2030. Science 319, 607-610. doi: 10.1126/science.1152339

Maunder, A. B. (1992). "Identification of useful germplasm for practical plant breeding programs," in Plant Breeding in the 1990s, eds H. T. Stalker and J. P. Murphy (Wallingford: CAB International), 147-169.

McKnight, T. D., Lillis, M. T., and Simpson, R. B. (1987). Segregation of genes transferred to one plant cell from two separate Agrobacterium strains. Plant Mol. Biol. 8, 439-445. doi: 10.1007/BF00017989

Meissner, R., Chague, V., Zhu, Q., Emmanuel, E., Elkind, Y., and Levy, A. (2000). Technical advance: a high throughput system for transposon tagging and promoter trapping in tomato. Plant J. 22, 265-274. doi: 10.1046/j.1365313x.2000.00735.x

Mendoza, E. M. T., Laurena, A. C., and Ramon Botella, J. (2008). Recent advances in the development of transgenic papaya technology. Biotechnol. Annu. Rev. 14, 423-462. doi: 10.1016/S1387-2656(08)00019-7

Motoyama, T., Amari, Y., Tandang-Silvas, M. R., Cabanos, C., Kimura, A., Yoshikawa, M., et al. (2010). Development of transgenic rice containing a mutated 
beta subunit of soybean beta-conglycinin for enhanced phagocytosis-stimulating activity. Peptides 31, 1245-1250. doi: 10.1016/j.peptides.2010.03.035

Pereira, A. (2000). A transgenic perspective on plant functional genomics. Transgenic Res. 9, 245-260. doi: 10.1023/A:1008967916498

Rommens, C. M., Bougri, O., Yan, H., Humara, J. M., Owen, J., Swords, K., et al. (2005). Plant-derived transfer DNAs. Plant Physiol. 139, 1338-1349. doi: $10.1104 / \mathrm{pp} .105 .068692$

Rommens, C. M., Humara, J. M., Ye, J., Yan, H., Richael, C., Zhang, L., et al. (2004). Crop improvement through modification of the plant's own genome. Plant Physiol. 135, 421-431. doi: 10.1104/pp.104.040949

Rommens, C. M. (2004). All-native DNA transformation: a new approach to plant genetic engineering. Trends Plant Sci. 9, 457-464. doi: 10.1016/j.tplants.2004.07.001

Russell, A. W., and Sparrow, R. (2008). The case for regulating intragenic GMOs. J. Agr. Environ. Ethic. 21, 153-181. doi: 10.1007/s10806-007-9074-5

Schaart, J. G., Krens, F. A., Pelgrom, K. T. B., Mendes, O., and Rouwendal, G. J. A. (2004). Effective production of marker-free transgenic strawberry plants using inducible site-specific recombination and a bifunctional selectable marker gene. Plant Biotechnol. J. 2, 233-240. doi: 10.1111/j.1467-7652.2004.00067.x

Schouten, H. J., Krens, F. A., and Jacobsen, E. (2006). Do cisgenic plants warrant less stringent oversight? Nat. Biotech. 24, 753-753. doi: 10.1038/nbt0706-753

Shan, Q., Wang, Y., Chen, K., Liang, Z., Li, J., Zhang, Y., et al. (2013). Rapid and efficient gene modification in rice and Brachypodium using TALENs. Mol. Plant. 6, 1365-1368. doi: 10.1093/mp/sss162

Shukla, V. K., Doyon, Y., Miller, J. C., DeKelver, R. C., Moehle, E. A., Worden, S. E., et al. (2009). Precise genome modification in the crop species Zea mays using zinc-finger nucleases. Nature 459, 437-441. doi: 10.1038/nature07992

Simmonds, N. W. (1993). Introgression and incorporation. Strategies for the use of crop genetic resources. Biol. Rev. 68, 539-562. doi: 10.1111/j.1469185X.1993.tb01243.x

Tanksley, S. D., and McCouch, S. R. (1997). Seed banks and molecular maps: unlocking genetic potential from the wild. Science 277, 1063-1066. doi: $10.1126 /$ science.277.5329.1063

The Royal Society. (2009). Reaping the Benefits: Science and the Sustainable Intensification of Global Agriculture. Report 11/09 RS1608. London: The Royal Society.

Townsend, J. A., Wright, D. A., Winfrey, R. J., Fu, F., Maeder, M. L., Joung, J. K., et al. (2009). High-frequency modification of plant genes using engineered zinc-finger nucleases. Nature 459, 442-445. doi: 10.1038/nature07845

Trindade, L. M., Horvath, B., Bachem, C., Jacobsen, E., and Visser, R. G. (2003). Isolation and functional characterization of a stolon specific promoter from potato (Solanum tuberosum L.). Gene 303, 77-87. doi: 10.1016/S0378-1119(02) 01147-2

Upadhyay, S. K., Kumar, J., Alok, A., and Tuli, R. (2013). RNA guided genome editing for target gene mutations in wheat. G3 (Bethesda) 3, 2233-2238. doi: $10.1534 / \mathrm{g} 3.113 .008847$

van der Vossen, E. A., Gros, J., Sikkema, A., Muskens, M., Wouters, D., Wolters, P., et al. (2005). The Rpi2blb2 gene from Solanum bulbocastanum is an Mi21 gene homolog conferring broad spectrum late blight resistance in potato. Plant J. 44, 208-222. doi: 10.1111/j.1365-313X.2005.02527.x

van der Vossen, E. A., Sikkema, A., te Lintel Hekkert, B., Gros, J., Stevens, P., Muskens, M., etal. (2003). An ancient R gene from the wild potato species Solanum bulbocastanum confers broad spectrum resistance to Phytophthora infestans in cultivated potato and tomato. Plant J. 36, 867-869. doi: 10.1046/j.1365-313X.2003.01934.x

Viswanath, V., and Strauss, S. H. (2010). Modifying plant growth the cisgenic way. Inform. Syst. Biotechnol. News Rep. 2010, 1-4.

Xie, K., and Yang, Y. (2013). RNA-Guided genome editing in plants using a CRISPR/Cas system. Mol. Plant 6, 1975-1983. doi: 10.1093/mp/sst119

Zhang, Y., Zhang, F., Li, X., Baller, J. A., Qi, Y., Starker, C. G., et al. (2013). Transcription activator-like effector nucleases enable efficient plant genome engineering. Plant Physiol. 161, 20-27. doi: 10.1104/pp.112.205179

Zuo, J., Niu, Q. W., Moller, S. G., and Chua, N. H. (2001). Chemical-regulated, site specific DNA excision in transgenic plants. Nat. Biotechnol. 19, 157-161. doi: $10.1038 / 84428$

Conflict of Interest Statement: The authors declare that the research was conducted in the absence of any commercial or financial relationships that could be construed as a potential conflict of interest.

Received: 05 February 2014; accepted: 22 July 2014; published online: 11 August 2014 Citation: Hou H, Atlihan N and Lu Z-X (2014) New biotechnology enhances the application of cisgenesis in plant breeding. Front. Plant Sci. 5:389. doi: 10.3389/fpls.2014.00389

This article was submitted to Plant Genetics and Genomics, a section of the journal Frontiers in Plant Science.

Copyright (C) $2014 \mathrm{Hou}$, Atlihan and Lu. This is an open-access article distributed under the terms of the Creative Commons Attribution License (CC BY). The use, distribution or reproduction in other forums is permitted, provided the original author(s) or licensor are credited and that the original publication in this journal is cited, in accordance with accepted academic practice. No use, distribution or reproduction is permitted which does not comply with these terms. 